DOI: https://doi.org/10.24127/ajpm.v10i3.3859

\title{
PENGARUH PENDEKATAN REALISTIC MATHEMATICS EDUCATION TERHADAP KETERAMPILAN BERPIKIR KRITIS MAHASISWA
}

\author{
Reni Setyaningsih $^{1 *}$, Haryanto $^{2}$, Nelly Rhosyida ${ }^{3}$ \\ ${ }^{1,2}$ Pendidikan Dasar, Program Pascasarjana, Universitas Negeri Yogyakarta, Indonesia \\ ${ }^{3}$ Pendidikan Guru Sekolah Dasar, Universitas Sarjanawiyata Tamansiswa, Indonesia \\ *Corresponding author. Jalan Colombo No. 1 Depok, Sleman, 55281, Yogyakarta, Indonesia \\ Jalan Batikan UH-III/1043, Yogyakarta, Indonesia \\ E-mail: $\quad$ renisetyaningsih.2019@student.uny.ac.id $^{\left.1^{*}\right)}$ \\ haryanto_tp@uny.ac.id ${ }^{2)}$ \\ rhosyidanelly@gmail.com $^{3)}$
}

Received 26 June 2021; Received in revised form 12 September 2021; Accepted 17 September 2021

\begin{abstract}
Abstrak
Keterampilan berpikir kritis penting untuk dikembangkan dalam diri mahasiswa, hal ini dikarenakan mempunyai peran yang penting untuk memahami sebuah permasalahan. Keterampilan berpikir kritis mampu ditingkatkan melalui pendekatan Realistic Mathematics Education (RME) karena dalam pembelajarannya mengutamakan process of doing mathematics sehingga mahasiswa mampu menemukan konsep matematikanya sehingga dapat digunakan untuk menyelesaikan suatu permasalahan. Tujuan dari riset yang telah dilangsungkan ialah menguji pengaruh positif pendekatan RME atas keterampilan berpikir kritis mahasiswa Pendidikan Guru Sekolah Dasar (PGSD) yang berada di Universitas Sarjanawiyata Tamansiswa (UST). Kuasi eksperimen merupakan jenis dari riset ini. Riset ini mengaplikasikan desain pretest-postest control group design. Riset ini memiliki sampel yang jumlahnya ialah 76 mahasiswa dari prodi PGSD yang berada di Universitas Sarjanawiayata Tamansiswa. Cluster random sampling merupakan teknik yang digunakan pada riset ini dalam penentuan jumlah sampel. Teknik pada pengumpulan data yakni memakai tes keterampilan berpikir kritis dengan jumlah lima soal pre-test dan lima soal pos-test. Analisis pada riset ini ialah menggunakan uji t guna menguji hipotesisnya. Riset ini membuktikan bahwa ada pengaruh yang positif kegiatan belajar mengajar yang menerapkan pendekatan RME terhadap keterampilan berpikir kritis mahasiswa menurut taraf signifikansi yakni 0,001 $<0,05$ yang menunjukkan bahwasanya $\mathrm{H}_{0}$ ditolak sehingga Ha otomatis diterima.
\end{abstract}

Kata kunci: Berpikir kritis; pendekatan; RME.

\begin{abstract}
Critical thinking skill is important to be developed in students as this skill has an important role in understanding problems. Critical thinking skills can be improved through the Realistic Mathematics Education (RME) approach as it prioritizes the process of doing mathematics in learning so that students can find mathematical concepts to solve a problem. This study aims to examine the positive effect of the RME approach on the critical thinking skill of Elementary School Teacher Education (PGSD) students at Universitas Sarjanawiyata Tamansiswa (UST). This quasi-experimental study used the pretest-posttest control group design. It involved 76 students from the PGSD study program at Universitas Sarjanawiyata Tamansiswa as samples. The number of samples was determined using the cluster random sampling technique. The data were collected by a critical thinking skills test with a total of five pre-test questions and five post-test questions. Then, the data were analyzed using the t-test to test the hypothesis. This study revealed that there is a positive effect of the RME approach on students' critical thinking skills with a significance level of $0.001<0.05$ which indicates that $H_{0}$ is rejected so that Ha is accepted.
\end{abstract}

Keywords: Approach; critical thinking; RME .

This is an open access article under the Creative Commons Attribution 4.0 International License 
DOI: https://doi.org/10.24127/ajpm.v10i3.3859

\section{PENDAHULUAN}

Satu diantara mata pelajaran yang memiliki peran penting dalam dunia pendidikan adalah matematika. Matematika dipelajari mulai sekolah dasar sampai perguruan tinggi. Kehidupan sehari-hari tentu sangat berkaitan dengan matematika (Cockcroft, 1982; Mashuri et al., 2020; Yuniati, 2012). Matematika merupakan suatu alat untuk mengembangkan cara berpikir, salah satunya yaitu berpikir kritis (Chrissanti \& Widjajanti, 2015; Mashuri et al., 2020; Mulbar \& Zaki, 2018; Widyastuti et al., 2014) . Berpikir kritis beserta matematika sulit untuk terpisahkan antar satu sama lainnya (Jacob, 2012). Upaya untuk mengembangkan keterampilan berpikir kritis telah menjadi agenda utama di banyak negara (Innabi \& El Sheikh, 2007; Mason et al., 2013; NCTM, 2000).

Pada abad 21 ini menuntut individu untuk memiliki keterampilan 4C yakni communication, critical thinking, collaboration, serta creativity. Hal ini sejalan dengan assessment \& teaching of $21^{\text {st }}$ century skills (ATC21S) yaitu peneliti dari 60 institusi dunia serta dilakukan oleh 250 peneliti mengkategorikan keterampilan yang harus dimiliki pada abad 21 yakni way of thinking (mencakup kreatifitas, berpikir kritis, memecahkan masalah, inovasi, serta mengambil sebuah keputusan), way of working (mencakup berkolaborasi serta berkomunikasi), tools for working (mencakup rasa tanggung jawab, hidup dan karir serta adanya kesadaran sebagai warga lokal dan global), dan yang terakhir adalah skills for living in the world (mencakup literasi teknologi informasi dan komunikasi serta literasi informasi).

Mengingat keterampilan berpikir kritis sangat penting untuk dimiliki, maka dalam pelaksanaan pembelajaran matematika di masa pandemi ini perlu diperhatikan. (Wahyuningrum \& Latifah, 2020) sistem pembelajaran mengalami perubahan dengan adanya wabah Coronavirus Disease (Covid19). Kegiatan belajar mengajar yang sebelumnya dilaksanakan secara tatap muka berubah menjadi online. Berdasarkan pengamatan yang telah dilakukan pada mahasiswa PGSD yang berada di Universitas Sarjanawiyata Tamansiswa, didapatkan fakta bahwa mahasiswa lebih banyak mendengarkan ceramah dari dosen. Selama perkuliahan mahasiswa tidak terlibat untuk mengkonstruksi pengetahuannya. Hal tersebut dibuktikan dengan selama perkuliahan, dosen berperan sebagai subjek dan mahasiswa langsung menerima hasil yang disampaikan oleh dosen. Selain itu selama perkuliahan berlangsung terlihat bahwa dosen lebih dominan. Hal tersebut terlihat dari mahasiswa yang sering diam serta tidak memberikan pertanyaan maupun mengutarakan pendapat kepada dosen. Hal tersebut mengindikasikan bahwasanya keterampilan berpikir kritis mahasiswa kurang. Sejalan dengan hal tersebut (Chrissanti \& Widjajanti, 2015; $\mathrm{N}$ et al., 2017) menyatakan bahwa pembelajaran yang didominasi oleh guru tidak efektif untuk keterampilan berpikir kritis.

Saat ini, pada era globalisasi penting bagi setiap individu untuk memiliki keterampilan berpikir kritis agar dapat mengatasi berbagai permasalahan. Sependapat terkait hal tersebut (Incikabi et al., 2013; Ku et al., 2017; Nugroho et al., 2018; Rahman et al., 2018; Wan \& Cheng, 2019) menguraikan bahwasanya keterampilan berpikir kritis menjadi hal yang perlu untuk dimiliki bagi setiap individu. Keterampilan berpikir kritis menggambarkan sebuah cara berpikir 
reflektif yang memfokuskan untuk menentukan apa yang akan ia percaya atau akan ia lakukan (Adeyemi, 2012; Ennis, 2015). Terdapat 6 aspek keterampilan berpikir kritis, yaitu focus, reason, inference situation, clarity, dan overview (Ennis, 2015).

Berdasarkan paparan diatas, menunjukkan bahwa dibutuhkan adanya alternative baru selama kegiatan belajar mengajar dimana mahasiswa dapat meningkatkan keterampilan berpikir kritisnya. Salah satunya yaitu menggunakan pendekatan Realistics Mathematics Education (RME). Hal tersebut diperkuat oleh penelitian yang dilakukan (Wijaya \& Irianti, 2021) yang mengungkapkan bahwa pendekatan RME dapat meningkatkan keterampilan berpikir kritis mahasiswa. RME diterapkan dengan menghubungkan hal yang nyata/ real sebagai sebuah pengalaman. (Gravemeijer, 1994) mengungkapkan bahwa terdapat tiga prinsip pada RME yakni pertama Guided reinvention dan progressive mathematizing, kedua Didactical phenomenology, kemudian yang terakhir ialah Self Development models. RME merupakan pendekatan untuk kegiatan belajar mengajar yang memberikan peluang bagi pebelajar secara aktif dengan membangun pengetahuannya (Arsaythamby \& Zubainur, 2014; Kusumaningrum \& Suparman, 2020).

Asas yang utama dalam kegiatan belajar mengajar adalah memberikan sebuah kesempatan pada mahasiswa agar mengembangkan kemampuannya untuk berpikir. Pendidikan saat ini menitikberatkan pada cara berpikir, salah satunya yaitu menjadi pemikir kritis (Aizikovitsh-Udi \& Amit, 2011). Setiap orang mengharapkan institusi apapun dapat membuat peserta didiknya untuk berpikir kritis (Seventika et al., 2018).
Beberapa penelitian yang pernah dilakukan memperlihatkan bahwa keterampilan berpikir kritis memiliki dampak yang positif. (Tee et al., 2018) mengungkapkan bahwa hasil penelitian menunjukkan keterampilan berpikir kritis mampu meningkatkan kemampuan penalaran matematis. (Jacob, 2012) menyatakan bahwasanya keterampilan berpikir kritis mampu meningkatkan prestasi dalam matematika. Keterampilan berpikir kritis dapat berakibat pada kepiawaian individu untuk mampu mengatasi suatu permasa-lahan dengan efektif (Ebiendele Ebosele Peter, 2012).

Menggunakan pendekatan RME dalam pembelajaran memiliki dampak positif. Penelitian yang dilakukan (Sitompul, 2021) menunjukkan bahwa menggunakan pendekatan RME ketika pandemi Covid-19 mampu meningkatkan pemahaman konsep serta keterampilan berpikir kreatif. Keadaan tersebut sependapat dengan riset yang telah dilakukan (Ningtias, 2020) dengan menerapkan pendekatan RME selama pandemi Covid-19 menunjukkan bahwa hasil pembelajaran matematika dan kemampuan untuk berpikir kreatif akan meningkat apabila guru menerapkan pendekatan yang tepat salah satunya yaitu RME. Penelitian yang dilakukan (Aldila Afriansyah et al., 2021) mengungkapkan bahwa keterampilan berpikir mahasiswa yang mendapatkan pembelajaran menggunakan pendekatan RME lebih baik dibandingkan dengan yang mendapatkan pembelajaran konvensional. Tujuan yang ada pada riset ini ialah guna menguji pengaruh positif pendekatan RME pada keterampilan berpikir kritis mahasiswa.

\section{METODE PENELITIAN}

Metode kuantitatif yang diaplikasikan pada riset ini berbentuk quasi experiment (eksperimen semu). Selama 
riset ini menyertakan dua kelas yang tak sama, yakni kelas kontrol serta kelas eksperimen. Mahasiswa yang berada di kelas kontrol melakukan kegiatan belajar mengajar dengan pendekatan konvensional. Sedangkan mahasiswa di kelas eksperimen diberikan treatment atau perlakuan dengan menerapkan pendekatan RME. Penelitian dilakukan pada April hingga Mei 2021 dengan materi FPB dan KPK di Universitas Sarjanawiyata Tamansiswa. Subjeknya adalah mahasiswa semester II program studi PGSD yang mengambil mata kuliah matematika kelas bawah sebanyak 76 mahasiswa dengan rincian dari kelas $\mathrm{F}$ terdapat 38 mahasiswa dan kelas $\mathrm{H}$ terdapat 38 mahasiswa.

Penentuan sampel dilakukan
dengan teknik Cluster random sampling. Riset ini menetapkan sampel yakni kelas $\mathrm{H}$ menjadi kelas yang diberikan perlakuan atau treatment (kelas eksperimen) sedangkan kelas $\mathrm{F}$ merupakan kelas untuk nantinya tak akan dikenakan perlakuan atau tidak diberi treatment (kelas kontrol). Pretestpostest control group design ialah desain yang dipergunakan untuk riset ini layaknya yang disajikan seperti Tabel 1 (Sugiyono, 2017).

Tabel 1. Rancangan Penelitian

\begin{tabular}{llll}
\hline KE & O1 & X & O2 \\
KK & O3 & - & O4 \\
\hline Keterangan & \\
KK & Kelas Kontrol \\
KE & : Kelas Eksperimen
\end{tabular}

Teknik yang diaplikasikan untuk mengumpulkan data yakni teknik tes. Instrumen yang dipergunakan untuk mengumpulkan data yakni soal essay dengan berjumlah 5 untuk pre-test serta 5 untuk pos-test. Instrumen tes ini digunakan untuk menguji keterampilan berpikir kritis mahasiswa.
Penelitian ini analisis datanya memanfaatkan teknik analisis deskriptif serta inferensial. Deskripsi untuk karakteristik variabel pada penelitian ini yaitu dilihat dari standar deviasi, skor rerata, serta varians yang diperoleh menggunakan analisis deskriptif. Sedangkan menggunakan analisis inferensial guna menguji ada tidaknya pengaruh dari pendekatan RME atas keterampilan berpikir kritis mahasiswa. Terdapat tiga pengujian yang akan diterapkan yakni melakukan uji normalitas sebagai uji prasyarat sebelum melaksanakan uji-t yang memiliki tujuan untuk melihat normalitas pada data yang didapatkan di pre-test serta pos-test, selanjutnya melakukan uji yang kedua yaitu uji homogenitas dengan menggunakan Leavene Test sebagai uji prasyarat bagi uji-t yang bertujuan untuk mengetahui homogen tidaknya pada data yang terdapat pada pre-test serta pos-tes, yang terakhir yaitu melakukan uji-t (Independent Sample T-test) yang mana memiliki tujuan guna menguji pengaruh positif pendekatan RME terhadap keterampilan berpikir kritis mahasiswa.

Apabila hasilnya untuk pengujian normalitas yang menggunakan ShapiroWilk memperlihatkan taraf sig > 0,05 dapat dikatakan data yang ditemukan berdistribusi normal. Selanjutnya untuk uji homogenitas menggunakan Lavene Test apabila mempunyai taraf sig $>0,05$ dapat dikatakan data tersebut termasuk homogen. Apabila uji prasyarat telah dilakukan dan memenuhi syarat, untuk berikutnya dilaksanakan pengujian hipotesis pada riset ini menggunakan uji t. Apabila taraf signifikansi yang didapatkan melalui uji $\mathrm{t}<0,05$ hal tersebut memperlihatkan $\mathrm{H}_{0}$ akan ditolak. Hipotesis dari riset ini yang akan diuji yaitu $\mathrm{H}_{0}=$ Tidak adanya pengaruh atau dampak yang signifikan 
DOI: https://doi.org/10.24127/ajpm.v10i3.3859

pada keterampilan berpikir kritis mahasiswa dengan kegiatan belajar mengajar yang menggunakan pendekatan RME. $\mathrm{H}_{1}=$ Terdapatnya pengaruh atau dampak yang signifikan pada keterampilan berpikir kritis mahasiswa dengan kegiatan belajar mengajar yang menggunakan pendekaran RME.

\section{HASIL DAN PEMBAHASAN}

Menurut riset yang dilakukan mulai tanggal 9 April sampai 23 April 2021 pada mahasiswa yang mengikuti semester II kelas H serta kelas F pada Universitas Sarjanawiyata Tamansiswa prodi PGSD ini yaitu mencakup analisis deskriptif dan analisis inferensial. Analisis deskriptif digunakan untuk menguraikan data yang diperoleh dari pre-test serta pos-test pada keterampilan berpikir kritis dari kelas eksperimen serta kelas kontrol yang mana mencakup skor rerata, standar deviasi beserta varians yang dipaparkan kedalam wujud deskriptif. Keterampilan berpikir kritis mahasiswa secara deskriptif dapat dilihat menurut hitungan rerata pre-test serta pos-test untuk kelas eksperimen beserta kelas kontrol disajikan kedalam Tabel 2. Sementara itu untuk rata-rata dari skor keterampilan berpikir kritis mahasiswa yang berada di kelas eksperimen serta kelas kontrol lebih jelasnya bisa dilihat melalui Gambar 1.

Tabel 2. Hasil dari analisis deskriptif keterampilan berpikir kritis kelas eksperimen (KE) serta kelas kontrol (KK).

\begin{tabular}{cccc}
\hline \multirow{2}{*}{ Data } & \multicolumn{3}{c}{ Deskriptif } \\
\cline { 2 - 4 } & Mean & $\begin{array}{c}\text { Stand } \\
\text { Dev }\end{array}$ & Varians \\
\hline Pretest $\mathrm{KK}$ & 63.20 & 9.89 & 98.01 \\
Pretest $\mathrm{KE}$ & 63.29 & 8.27 & 68.53 \\
Postest $\mathrm{KK}$ & 71.53 & 11.01 & 121.25 \\
Posteset $\mathrm{KE}$ & 80.29 & 11.74 & 138.02 \\
\hline
\end{tabular}

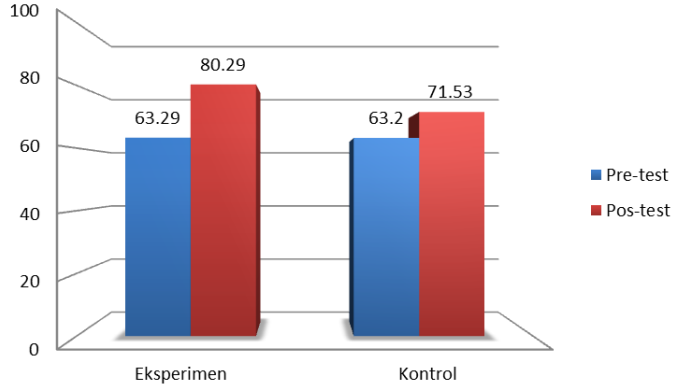

Gambar 1. Rerata skor keterampilan berpikir kritis.

Berdasarkan pada Gambar 1 dapat diketahui bahwa mahasiswa kelas eksperimen mempunyai peningkatan skor rata-rata keterampilan berpikir kritis sebesar 17.00. Sementara itu mahasiswa pada kelas kontrol mempunyai kenaikan rata-rata sebesar 8.33. Maksud dari hasil hitungan tersebut membuktikan bahwa mahasiswa kelas eksperimen mengalami kenaikan rerata yang lebih besar keterampilan berpikir kritisnya daripada kelas kontrol. Sebelum ditelaah secara inferensial dengan maksud membuktikan pengaruh atau dampak pendekatan RME terhadap keterampilan berpikir kritis, dilaksanakan uji asumsi, pertama-tama yakni uji normalitas dan juga uji homogenitas. Hasil yang dikantongi pada pengujian normalitas terkandung pada Tabel 3 .

Tabel 3. Hasil uji normalitas pre-tes dan pos-test.

\begin{tabular}{ccc}
\hline No & Data & $\begin{array}{c}\text { Nilai Sig. } \\
\text { Berpikir Kritis }\end{array}$ \\
\hline 1 & Pretes KK & 0.077 \\
2 & Pretes KE & 0.082 \\
3 & Postes KK & 0.111 \\
4 & Postes KE & 0.202 \\
\hline
\end{tabular}

Dari Tabel 3 didapatkan informasi yakni hasil untuk pengujian normalitas data kelas eksperimen beserta kelas kontrol memiliki taraf signifikansi $>0.05$, sehingga data tersebut terbilang berdistribusi normal. Lavene Test 
DOI: https://doi.org/10.24127/ajpm.v10i3.3859

dipergunakan untuk melakukan analisis homogenitas yang hasilnya disajikan seperti Tabel 4.

Tabel 4. Uji homogenitas

\begin{tabular}{ccc}
\hline No & Data & Nilai sig. \\
\hline 1 & Pretest & 0.253 \\
2 & Postest & 0.954 \\
\hline
\end{tabular}

Bersumber pada Tabel 4 pengujian homogenitas dengan Lavene Test pada data pre-test serta pos-test menunjukkan nilai signifikansi > 0.05 yang menunjukkan data homogen. Berdasarkan uji prasyarat yang telah dilakukan diperoleh hasil kedua kelas berdistribusi normal dan homogen. Oleh karena itu dapat dilanjutkan ke uji t.

Uji t bermaksud guna membuktikan pengaruh atau dampak positif pendekatan RME atas keterampilan berpikir kritis mahasiswa. Hasil yang ditemukan melalui uji-t dipaparkan melalui Tabel 5.

Tabel 5. Hasil uji Independent T test

\begin{tabular}{cccc}
\hline Kondisi & $\mathbf{t}_{\text {hitung }}$ & Df & Sig \\
\hline Pre-test & 0.045 & 81 & 0.964 \\
Pos-test & 3.490 & 81 & 0.001 \\
\hline
\end{tabular}

Berlandaskan Tabel 5 didapati nilai signifikansi untuk data pre-test $>0.05$. Sedangkan didapatkan nilai signifikansi pos-test yakni $<0.05$ berarti yaitu terdapatnya perbedaan yang signifikan dari kelas eksperimen maupun kelas kontrol. Bersumber pada data yang diperoleh hasil $\mathrm{H}_{0}$ ditolak, jadi $\mathrm{H}_{1}$ diterima. Akibatnya dapat dikatakan bahwa adanya pengaruh ataupun dampak yang positif pada kegiatan belajar mengajar yang mana menggunakan pendekatan RME atas keterampilan berpikir kritis yang dimiliki mahasiswa. Pendek kata dikatakan bahwa keterampilan berpikir kritis mahasiswa mengantongi nilai rerata yang lebih tinggi apabila dibandingkan dengan hasil nilai rerata mahasiswa yang menerapkan pembelajaran dengan powerpoint dan ceramah.

Hal ini dikarenakan pembelajaran dengan menggunakan pendekatan RME membuat mahasiswa secara aktif mengkonstruk pengetahuannya sehingga akan lebih memahami dan mengerti apa yang telah dipelajarinya. Menggunakan RME untuk proses kegiatan belajar mengajar mampu mengembangkan dan menyempurnakan pemahaman mereka tentang matematika (Zandieh \& Rasmussen, 2010). Pendekatan RME didasarkan pada kehidupan yang ada di sehari-hari serta melibatkan pebelajar ketika kegiatan belajar mengajar matematika. Keikutsertaan peserta didik dalam kegiatan belajar mengajar akan memberi pengalaman yang bermakna. Menggunakan pendekatan RME ketika kegiatan belajar mengajar akan menyalurkan imbas yang positif teruntuk peserta didik. Penelitian yag dilakukan oleh (Yudha \& Suwarjo, 2014) memper-lihatkan bahwa proses kegiatan belajar mengajar menggunaka RME mampu meningkatkan kepercayaan diri peserta didik. Penelitian berikutnya dilakukan oleh (Sukri \& Widjajanti, 2015) menunjukkan bahwa menggunakan RME dalam proses belajar peserta didik mampu meningkatkan prestasinya hal tersebut dikarenakan peserta didik ikut berpatisipasi dengan aktif dalam belajarnya, peserta didik tidak akan berperan sebagai objek, namun akan berperan sebagai subjek dalam kegiatan belajar mengajar. Hal tersebut sepaham dengan penelitian yang pernah dilaku-kan (Asih, 2017) yang mengutarakan kegiatan belajar mengajar menggunakan pendekatan RME mampu menaikkan keterampilan berpikir kritis seorang individu. 
DOI: https://doi.org/10.24127/ajpm.v10i3.3859

Menurut hasil dari riset ini, menggunakan pendekatan RME dalam pembelajaran memiliki pengaruh atau dampak positif atas keterampilan berpikir kritis mahasiswa. Keterampilan berpikir kritis adalah sebuah upaya yang dilangsungkan oleh seorang individu guna mengumpulkan berbagai informasi, menafsirkannya, lalu menganalisisnya, kemudian mengevaluasi informasi yang didapatkan untuk menyimpulkan hasil yang valid (Chukwuyenum, 2013). Adanya pengaruh yang positif didasarkan dari meningkatnya keterampilan berpikir kritis sebelum dengan sesudah kegiatan belajar mengajar yang menerapkan pendekatan RME. Hal tersebut terbukti bahwa menerapkan pendekatan RME di kelas eksperimen memperoleh respon ataupun tanggapan yang lebih positif karena dapat menumbuhkan keterampilan berpikir kritis mahasiswa dengan lebih tinggi apabila membandingkannya dengan di kelas kontrol yang mengaplikasikan kegiatan belajar mengajar secara konvensional. Sejalan dengan penelitian yang dilakukan oleh (Amalia et al., 2019; Cahyaningsih \& Nahdi, 2021; Taubah, 2018) menunjukkan bahwa menggunakan pendekatan RME mampu meningkatkan keterampilan berpikir kritis mahasiswa.

RME merupakan pendekatan untuk kegiatan belajar mengajar matematika yang menitikberatkan dari hal yang "real" dan penekanannya pada "process of doing mathematics" untuk menemukan sendiri yang akhirnya akan mengaplikasikan matematika dalam penyelesaian masalah baik itu secara individu ataupun juga kelompok. Sejalan dengan hal tersebut terdapat lima karakteristik RME, (Heuvelpanhuizen et al., 2014) mengungkapkan yakni memakai konteks nyata, memakai berbagai model, adanya kontribusi peserta didik, serta yang terakhir ialah adanya keterkaitan serta interaktivitas. Dengan hal tersebut maka akan terjadi komunikasi dua arah yang melibatkan antara mahasiswa dengan dosen, dimana hal tersebut akan berdampak pada keterampilan berpikir logis, pemecahan masalah, dan berpikir kritis mahasiswa. Hasil dari penelitian yang dilakukan (Palinussa, 2013) menunjukkan bahwa menggunakan pendekatan RME ketika kegiatan belajar mengajar mampu mengembangkan keterampilan berpikir kritis mahasiswa.

Melalui kegiatan belajar mengajar menggunakan RME mahasiswa dapat lebih memandang kegiatan belajar mengajar matematika sebagai suatu bentuk usaha untuk pemecahan masalah dalam kehidupan sehingga mempunyai motivasi yang lebih tinggi. Melalui dihadapkan suatu masalah, setelah itu mahasiswa diminta untuk memecahkan masalah tersebut dengan mencari data serta melakukan eksperimentasi untuk membuktikan kajian data sehingga mengarah pada penemuan konsep yang saat itu sedang dipelajari. Di setiap kegiatan belajar mengajar, mahasiswa memperoleh sebuah kesempatan untuk menerapkan pengetahuan sebelumnya yang telah dimilikinya serta melatih keterampilan dan juga kemampuannya dalam proses berpikir.

Membelajarkan matematika kepada mahasiswa agar mampu menguasai kompetensi pada matematika tidak terletak dari banyaknya suatu konsep yang harus dihafal, melainkan lebih ditekankan agar mahasiswa berlatih untuk lebih mengasah kemampuan berpikirnya dengan menemukan konsep matematis melalui pengalaman. RME mempunyai tujuan untuk merubah matematika selama pembelajaran menjadi lebih bermakna serta 
menyenangkan (Laurens et al., 2018; Suciana et al., 2020). Untuk memberikan pengalaman secara nyata kepada mahasiwa, maka harus dilibatkan dengan aktif yaitu melalui adanya interaksi ketika pembelajaran. Hal tersebut tentunya sejalan dengan karakteristik RME yaitu menggunakan masalah yang kontekstual, adanya kontribusi serta adanya interaktiivtas (Gravemeijer, 1994)

Abad 21 ini mengharuskan individu untuk memiliki salah satu keterampilan yakni keterampilan berpikir kritis (Aizikovitsh-Udi \& Cheng, 2015; Kalelioğlu \& Gülbahar, 2013; Kriel, 2013). Pentingnya mahasiswa untuk memiliki keterampilan berpikir ketika berlangsungnya kegiatan belajar mengajar matematika memberikan akibat pada pola mahasiswa agar mampu menuntaskan suatu masalah serta mampu untuk menarik suatu keputusan atau hasil secara logis. Faktor yang bisa mempengaruhi hasil belajar salah satunya yaitu karakteristik mahasiswa dalam berpikir, salah satunya yaitu keterampilan berpikir kritis (Rochmad et al., 2018). Tidak hanya itu keterampilan berpikir kritis harus diperhatikan dan dikembangkan dengan baik, hal dikarenakan untuk bekal pada kehidupan di masa yang akan datang. (Risnawati, 2013) menjelaskan bahwa pendekatan RME merupakan pendekatan yang membelajarkan mahasiswa untuk membangun sendiri pengetahuannya melalui berpikir kritis dalam menyelesaikan suatu permasalahan, dengan pembiasaan untuk menyelesaikan suatu masalah mampu memberi bekal pada peserta didik agar mampu mengatasi suatu permasalahan yang relevan dengan kehidupan

\section{KESIMPULAN DAN SARAN}

Berlandaskan riset serta pembahasan yang telah dilangsungkan ditemukan fakta yaitu ketika kegiatan belajar mengajar menggunakan RME terjadi peningkatan keterampilan berpikir kritis daripada kelas yang menerapkan kegiatan belajar mengajar dengan konvensional. Hal ini dibuktikan dari hasil analisis deskriptif yang menunjukkan peningkatan skor rata-rata keterampilan berpikir kritis dari 63.29 menjadi 80.29. Selain itu hasil dari analisis inferensial menunjukkan nilai signifikansi yang diperoleh $0.001<0.05$ sehingga $\mathrm{H}_{0}$ ditolak dan $\mathrm{Ha}$ diterima. Berlandaskan hal tersebut sehingga ditarik benang merah bahwa terdapat pengaruh yang positif pendekatan RME terhadap keterampilan berpikir kritis mahasiswa.

Dari hasil riset disarankan bahwa dalam pembelajaran perlu dilakukan pemilihan suatu pendekatan pembelajaran yang tepat dan sesuai dengan materi. Bagi peneliti yang lain dapat melakukan sebuah pengkajian yang lebih mendalam lagi terkait pengaruh pendekatan RME terhadap keterampilan berpikir kritis mahasiswa.

\section{DAFTAR PUSTAKA}

Adeyemi, S. B. (2012). Developing critical thinking skills in students: A mandate for higher education in Nigeria. European Journal of Educational Research, 1(2), 155161. https://doi.org/10.12973/eujer.1.2.155

Aizikovitsh-Udi, E., \& Amit, M. (2011). Developing the skills of critical and creative thinking by probability teaching. Procedia - Social and Behavioral Sciences, 15, 10871091. https://doi.org/10.1016/j.sbspro.201 1.03.243

Aizikovitsh-Udi, E., \& Cheng, D. (2015). 
DOI: $\underline{\text { https://doi.org/10.24127/ajpm.v10i3.3859 }}$

Developing Critical Thinking Skills from Dispositions to Abilities: Mathematics Education from Early Childhood to High School. Creative Education, 06(04), 455-462. https://doi.org/10.4236/ce.2015.640 45

Aldila Afriansyah, E., Herman, T., Turmudi, \& Afgani Dahlan, J. (2021). Critical thinking skills in mathematics. Journal of Physics: Conference Series, 1778(1). https://doi.org/10.1088/17426596/1778/1/012013

Amalia, N. F., Subanji, \& Untari, S. (2019). Kemampuan Berpikir Kritis Siswa Melalui Penerapan Pendekatan Realistic Mathematics Education Berbantuan Media Manipulatif Origami. Jurnal Pendidikan: Teori, Penelitian, Dan Pengembangan, vol: 4, no(1), 1084-1091.

Arsaythamby, V., \& Zubainur, C. M. (2014). How a Realistic Mathematics Educational Approach Affect Students' Activities in Primary Schools? Procedia - Social and Behavioral Sciences, 159, 309313.

https://doi.org/10.1016/j.sbspro.201 4.12.378

Asih, A. K. E. B. I. \& C. S. (2017). Penerapan Realistic Mathematics Education Untuk Meningkatkan Kemampuan Berpikir Kritis Siswa Kelas V. Jurnal Pendidikan, 2(4), 524-530.

http://journal.um.ac.id/index.php/jp tpp/article/view/8787

Cahyaningsih, U., \& Nahdi, D. S. (2021). The Effect of Realistic Mathematics Education on Elementary Students' Critical Thinking Skills. Journal of Physics: Conference Series, 1764(1). https://doi.org/10.1088/17426596/1764/1/012127

Chrissanti, M. I., \& Widjajanti, D. B.
(2015). Keefektifan Pendekatan Metakognitif Ditinjau Dari Prestasi Belajar, Kemampuan Berpikir Kritis, Dan Minat Belajar Matematika. Jurnal Riset Pendidikan Matematika, 2(1), 51. https://doi.org/10.21831/jrpm.v2i1. 7150

Chukwuyenum, A. N. (2013). Impact of Critical thinking on Performance in Mathematics among Senior Secondary School Students in Lagos State. IOSR Journal of Research \& Method in Education (IOSRJRME), 3(5), 18-25. https://doi.org/10.9790/73880351825

Cockcroft, W. . (1982). Mathematics Counts. Report of the Committee of Inquiry into the Teaching of Mathematics in Schools in England and Wales, ix-311.

Ebiendele Ebosele Peter. (2012). Ebiendele Ebosele Peter. (2012). Critical thinking: Essence for teaching mathematics and mathematics problem solving skills. African Journal of Mathematics and Computer Science Research, 5(3), 39-43.

https://doi.org/10.5897/ajmcsr11.16 1Critical thinking: . African Journal of Mathematics and Computer Science Research, 5(3), 39-43. https://doi.org/10.5897/ajmcsr11.16 1

Ennis, R. H. (2015). The Nature of Critical Thinking: Outlines of General Critical Thinking Disposition and Abilities. Sixth International Conference on Thinking at MIT, 2013, 1-8. http://criticalthinking.net/wpcontent/uploads/2018/01/TheNature-of-Critical-Thinking.pdf

Gravemeijer, K. P. E. (1994). Developing realistic mathematics education. Faculty of Sciences, Freudenthal Institute, 13(3), $200 \mathrm{pp}$. 
DOI: https://doi.org/10.24127/ajpm.v10i3.3859

http://www.cdbeta.uu.n1/tdb/fulltext /199503-

terwel2.pdf\%0Ahttp://www.fisme.s cience.uu.nl/toepassingen/20014/

Heuvel-panhuizen, M. Van Den, Drijvers, P., Education, M., Sciences, B., \& Goffree, F. (2014). Encyclopedia of Mathematics Education. Encyclopedia of Mathematics Education.

https://doi.org/10.1007/978-94-0074978-8

Incikabi, L., Tuna, A., \& Biber, A. C. (2013). An Analysis Of Mathematics Teacher Candidates Critical Thinking Dispositions And Their Logical Thinking Skills. Journal of International Education Research (JIER), 9(3), 257-266. https://doi.org/10.19030/jier.v9i3.7 884

Innabi, H., \& El Sheikh, O. (2007). The change in mathematics teachers' perceptions of critical thinking after 15 years of educational reform in Jordan. Educational Studies in Mathematics, 64(1), 45-68. https://doi.org/10.1007/s10649005-9017-x

Jacob, S. M. (2012). Mathematical achievement and critical thinking skills in asynchronous discussion forums. Procedia - Social and Behavioral Sciences, 31(2011), 800-804.

https://doi.org/10.1016/j.sbspro.201 1.12.144

Kalelioğlu, F., \& Gülbahar, Y. (2013). The effect of instructional techniques on critical thinking and critical thinking dispositions in online discussion. Educational Technology and Society, 17(1), 248-258.

Kriel, C. (2013). Creating a disposition for critical thinking in the mathematics classroom. Proceedings of the Second Biennial Conference of the South African Society for Engineering Education,
$11-12$ June, 67-75.

Ku, K. Y. L., Lee, V. S. L., \& Ellis, J. W. (2017). Using artwork as problem context in generic critical thinking instruction: A strategy for thoughts. Thinking Skills and Creativity, 25, 53-59.

https://doi.org/10.1016/j.tsc.2017.0 7.001

Kusumaningrum, H., \& Suparman. (2020). Design of social arithmetic students worksheets with rme approaches to improve critical thinking ability. International Journal of Scientific and Technology Research, 9(3), 49784982.

Laurens, T., Batlolona, F. A., Batlolona, J. R., \& Leasa, M. (2018). How does realistic mathematics education (RME) improve students' mathematics cognitive achievement? Eurasia Journal of Mathematics, Science and Technology Education, 14(2), 569578.

https://doi.org/10.12973/ejmste/769 59

Mashuri, S., Jahring, \& Nasruddin. (2020). Student Teams Achievement Divisions (STAD) dengan Pendekatan Realistic Mathematics Education (RME) Terhadap Kemampuan Pemahaman Matematis. AKSIOMA: Jurnal Program Studi Pendidikan Matematika, 9(4), 909-916. https://doi.org/https://doi.org/10.24 127/ajpm.v9i4.2979

Mason, J., Burton, L., \& Stacey, K. (2013). Thinking mathematically. In Early Years Educator (Vol. 15, Issue https://doi.org/10.12968/eyed.2013. 15.2.18

Mulbar, U., \& Zaki, A. (2018). Design of Realistic Mathematics Education on Elementary School Students. Journal of Physics: Conference Series, 1028(1). 
DOI: https://doi.org/10.24127/ajpm.v10i3.3859

https://doi.org/10.1088/17426596/1028/1/012155

N, S., Wahyudin, \& T, H. (2017). The Increase of Critical Thinking Skills through Mathematical Investigation Approach. Journal of Physics: Conference Series, 755(1). https://doi.org/10.1088/17426596/755/1/011001

NCTM. (2000). Pssm. Journal of Equine Veterinary Science, 18(11), 719. https://doi.org/10.1016/s07370806(98)80482-6

Ningtias, Y. (2020). APPLICATION OF A REALISTIC MATHEMATICS EDUCATION ( RME ) APPROACH TO IMPROVE STUDENT , S MATHEMATIC CREATIVE THINKING ABILITY DURING ( RME ) APPROACH TO IMPROVE STUDENT , $S$ MATHEMATIC CREATIVE THINKING ABILITY DURING THE COVID-19. December.

Nugroho, P. B., Nusantara, T., As'ari, A. R., Sisworo, Hidayanto, E., \& Susiswo. (2018). Critical thinking disposition: Students skeptic in dealing with ill-logical mathematics problem. International Journal of Instruction, 11(3), 635-648. https://doi.org/10.12973/iji.2018.11 $343 a$

Palinussa, A. L. (2013). Students' Critical Mathematical Thinking Skills and Character: IndoMS.J.M.E, 4(1), 7594.

Rahman, A., Ahmar, A. S., Arifin, A. N. M., Upu, H., Mulbar, U., Alimuddin, Arsyad, N., Ruslan, Rusli, Djadir, Sutamrin, Hamda, Minggi, I., Awi, Zaki, A., Ahmad, A., \& Ihsan, H. (2018). The Implementation of APIQ Creative Mathematics Game Method in the Subject Matter of Greatest Common Factor and Least Common Multiple in Elementary School. Journal of Physics:
Conference Series, 954(1). https://doi.org/10.1088/17426596/954/1/012011

Risnawati. (2013). Pengaruh Pendekatan Realistic Mathematics Education dengan Mind Mapping Terhadap Kemampuan Berpikir Kritis dengan Self-Efficacy Mahasiswa. 6(1), 3745.

Rochmad, Agoestanto, A., \& Kharis, M. (2018). Characteristic of critical and creative thinking of students of mathematics education study program. Journal of Physics: Conference Series, 983(1). https://doi.org/10.1088/17426596/983/1/012076

Seventika, S. Y., Sukestiyarno, Y. L., \& Mariani, S. (2018). Critical thinking analysis based on Facione (2015) Angelo (1995) logical mathematics material of vocational high school (VHS). Journal of Physics: Conference Series, 983(1). https://doi.org/10.1088/17426596/983/1/012067

Sitompul, O. (2021). LEARNING MATHEMATICS WITH A REALISTIC APPROACH IN OVERCOMING THE UNDERSTANDING OF MATHEMATICAL CONCEPTS AND STUDENTS ' CREATIVE THINKING SKILLS IN THE MIDDLE OF PANDEMI COVID 19. January.

Suciana, F., Musdi, E., \& Arnawa, I. M. (2020). Pengembangan Alur Belajar Berbasisrealistic Mathematic Education (Rme) Pada Materi Lingkaran. AKSIOMA: Jurnal Program Studi Pendidikan Matematika, 9(2), 369-377. https://doi.org/10.24127/ajpm.v9i2. 2769

Sugiyono. (2017). Metode Penelitian Pendidikan. Alfabeta.

Sukri, Y. F., \& Widjajanti, D. B. (2015). Pengaruh Pendekatan Rme 
DOI: https://doi.org/10.24127/ajpm.v10i3.3859

Terhadap Motivasi Dan Prestasi Belajar Siswa Sd Melalui Pembelajaran Tematik-Integratif. Jurnal Prima Edukasia, 3(2), 227. https://doi.org/10.21831/jpe.v3i2.65 03

Taubah, R. (2018). Student Critical Thinking Viewed from Mathematical Self-efficacy in Means Ends Analysis Learning with the Realistic Mathematics Education Approach. Unnes Journal of Mathematics Education Research, 7(2), 189-195. http://journal.unnes.ac.id/sju/index. php/ujmer

Tee, K. N., Leong, K. E., \& Abdul Rahim, S. S. (2018). The Mediating Effects of Critical Thinking Skills on Motivation Factors for Mathematical Reasoning Ability. Asia-Pacific Education Researcher, 27(5), 373-382. https://doi.org/10.1007/s40299018-0396-z

Wahyuningrum, A. S., \& Latifah, T. (2020). Investigating mathematical conversation in remote learning of mathematics during the covid-19 pandemic. Jurnal Riset Pendidikan Matematika, 7(2), 148-162. https://journal.uny.ac.id/index.php/j $\mathrm{rpm} /$ article/view/34841/14993

Wan, Z. H., \& Cheng, M. H. M. (2019). Classroom learning environment, critical thinking and achievement in an interdisciplinary subject: a study of Hong Kong secondary school graduates. Educational Studies, 45(3), 285-304. https://doi.org/10.1080/03055698.2 018.1446331

Widyastuti, N. S., Pujiastuti, P., \& Yogyakarta, U. N. (2014). Pengaruh Pendidikan Matematika Realistik Indonesia (PMRI) terhadap Pemahaman Konsep dan ... Nur Sri Widyastuti, Pratiwi Pujiastuti 183. Prima Edukasia, 2(2), 183-193.
Wijaya, E. M. S., \& Irianti, N. P. (2021). Meningkatkan Kemampuan Berpikir Kritis Mahasiswa Melalui Realistic Mathematic Education (RME). AKSIOMA: Jurnal Program Studi Pendidikan Matematika, 10(2), 648-658. https://doi.org/https://doi.org/10.24 127/ajpm.v10i2.3103

Yudha, C. B., \& Suwarjo, S. (2014). Peningkatan Kepercayaan Diri Dan Proses Belajar Matematika Menggunakan Pendekatan Realistik Pada Siswa Sekolah Dasar. Jurnal Prima Edukasia, 2(1), 42. https://doi.org/10.21831/jpe.v2i1.26 43

Yuniati, S. (2012). Menentukan Kelipatan Persekutuan Terkecil (KPK) Dan Faktor Persekutuan Terbesar (FPB) Dengan Menggunakan Metode "PEBI." 5(2), 149-165.

Zandieh, M., \& Rasmussen, C. (2010). Defining as a mathematical activity: A framework for characterizing progress from informal to more formal ways of reasoning. Journal of Mathematical Behavior, 29(2), 57-75. https://doi.org/10.1016/j.jmathb.20 10.01.001 